\title{
Attachment Style, Complicated Grief and Post-Traumatic Growth in Traumatic Loss: The Role of Intrusive and Deliberate Rumination
}

\author{
Hyu Jung Huh¹, Kyung Hee Kim², Hee-Kyung Lee², and Jeong-Ho Chae ${ }^{3 凶}$ \\ 1'Department of Psychiatry, Incheon St. Mary's Hospital, The Catholic University of Korea College of Medicine, Seoul, Republic of Korea \\ ${ }^{2}$ Department of Psychology, The Catholic University of Korea, Bucheon, Republic of Korea \\ ${ }^{3}$ Department of Psychiatry, Seoul St. Mary's Hospital, The Catholic University of Korea College of Medicine, Seoul, Republic of Korea
}

\begin{abstract}
Objective The present study examines the effects of attachment styles on the grief response and the indirect effect of rumination in parents who lost a child in the Sewol Ferry accident.

Methods Bereaved parents $(\mathrm{n}=81)$ completed self-report questionnaires evaluating their attachment style (Experience in Close Relationship-Short form), traumatic loss related rumination (Event-Related Rumination Inventory), degree of complicated grief (Inventory of Complicated Grief), and post-traumatic growth (Post-Traumatic Growth Inventory). Data were analyzed using correlation analysis, structural equation modeling, and bootstrapping.

Results The indirect effect of event-related intrusive rumination was significant in the relationship between attachment avoidance and complicated grief. The path from attachment avoidance to post-traumatic growth via deliberate rumination was not significant. With respect toattachment anxiety and post-traumatic growth, the indirect effect of deliberate rumination was significant. But the indirect effect of intrusive rumination was not significant in the relationships among attachment anxiety, complicated grief, and post-traumatic growth.

Conclusion Individuals with attachment anxiety could obtain post-traumatic growth via deliberate rumination. By contrast, attachment avoidance was associated with the risk of maladaptive grief. Grief interventions should account for individual differences in attachment styles through interventions that manage intrusive rumination and strengthen deliberate rumination.
\end{abstract}

Psychiatry Investig 2020;17(7):636-644

Key Words Attachment, Complicated grief, Post-traumatic growth, Traumatic loss, Rumination.

\section{INTRODUCTION}

Bereavement, especially following a traumatic loss, is a highly stressful life processthat is associated with decrements in mental health. ${ }^{1}$ Some people suffer from complicated or prolonged grief symptoms, whereas other individuals experience post-traumatic growth. ${ }^{2,3}$ Several previous studies have considered the risk factors and protective factors that are associated with bereavement outcomes.

Of the several factors that can influence bereavement outcomes, insecure attachment has received growing attention

Received: October 30, 2019 Revised: February 27, 2020

Accepted: March 27, 2020

$\triangle$ Correspondence: Jeong-Ho Chae, MD, PhD

Department of Psychiatry, Seoul St. Mary's Hospital, The Catholic University of Korea College of Medicine, 222 Banpodae-ro, Seocho-gu, Seoul 06591, Republic of Korea

Tel: +82-2-2258-6083, Fax: +82-2-2258-3870, E-mail: alberto@catholic.ac.kr (ac) This is an Open Access article distributed under the terms of the Creative Commons Attribution Non-Commercial License (https://creativecommons.org/licenses/bync/4.0) which permits unrestricted non-commercial use, distribution, and reproduction in any medium, provided the original work is properly cited. as important in the grieving process. ${ }^{4,5}$ Adult attachment theory describes two dimensions of insecure attachment, attachment anxiety and attachment avoidance. ${ }^{6,7}$ Individuals with attachment anxiety tend to be dependent on their relationships, constantly worrying that others will be unavailable or abandon them in situations of need. ${ }^{8}$ When the attachment figure is unavailable, the anxiously attached person tends to use hyper-activating strategies such as crying or clinging to restore proximity. ${ }^{9}$ Individuals with avoidant attachment have a tendency to mistrust others' motives and good will and thus attempt to maintain emotional distance in relationships. ${ }^{8}$ They prefer self-reliance and are reluctant to disclose their feelings. ${ }^{10}$ They tend to use deactivating strategies when attachment figures are perceived as unavailable, attempting to restore self-sufficiency by defensively inhibiting distress and proximity seeking. ${ }^{11}$ In the context of an interpersonal emotional regulation framework, attachment security has been thoughtto play an important role in the grieving process. ${ }^{5} \mathrm{~A}$ few researchers have suggested that a bereaved person's griev- 
ing behavior is modulated by his/her attachment style, such that insecure attachment (attachment anxiety or avoidance) can disrupt the normal process of recovery from loss. ${ }^{5}$

Several empirical studies have investigated the potential association between complicated or prolonged grief and attachment style. Most of them have shown an association between complicated grief and attachment anxiety, but the results for attachment avoidance are inconsistent. ${ }^{12}$ Several researchers have also explored the relationship between posttraumatic growth and attachment style. Two previous studies suggested that a higher level of attachment avoidance was related to lower post-traumatic growth in individuals who suffered from life-threatening trauma or violent loss. ${ }^{13,14}$ On the other hand, several previous studies found that attachment anxiety was positively associated with post-traumatic growth. $^{15,16}$

Taken together, the previous literature suggests that individuals with different attachment stylesmight travel distinct pathways to complicated grief and post-traumatic growth. However, the cognitive process that mediates between different attachment styles and complicated grief or post-traumatic growth is still unclear.

Multiple studies have explored the cognitive factors that can contribute to differences in bereavement outcomes. Of them, rumination has been extensively examined in relation to psychopathology, including post-traumatic stress disorder and complicated grief. Rumination is generally defined as "a mode of responding to distress that involves repetitively and passively focusing on symptoms of distress and on the possible cause and consequence of these symptoms." ${ }^{\prime 7}$ Although rumination is generally associated with depression, it has also been observed after traumatic events, and although ruminative thoughts in depressed people are typically maladaptive, rumination about a traumatic event can contribute post-traumatic growth. ${ }^{18}$ Rumination is considered to be a mechanism for restoring individual beliefs about the world that were broken by the traumatic event. ${ }^{19}$ In such a context, Cann et al. ${ }^{20}$ proposed two types of event rumination: intrusive and deliberate. Intrusive ruminations are unsolicited repetitive invasions of thought about traumatic events that one does not bring to mind voluntarily, and deliberate ruminations about events are engaged in voluntarily and can be used to purposely try to understand events and their implications.

Based on this theoretical background of intrusive and deliberate rumination, it can be inferred that individuals with a high level of intrusive rumination usually focus on the negative aspects of loss and fail to deal with other issues of concern, which in turn could increase the complicated grief response. Regardless of one's stable predisposition to engage in intrusive or deliberate thinking, a stressful life event can provoke both types of thinking. ${ }^{21}$ Furthermore, intrusive rumination could stimulate attempts to engage in more deliberate processing of one's experience. ${ }^{20}$ Therefore, both types of rumination could be important cognitive factors in growth after trauma.

Previous studies have suggested that the cognitive styles or coping strategies of the two different dimensions of insecure attachment could contribute to their distinctive pathways to a psychological response in stressful situations. ${ }^{22-24} \mathrm{Re}-$ garding intrusive rumination, many studies have revealed that both attachment anxiety and attachment avoidance correlate with a dysfunctional ruminative process. ${ }^{25-27}$ Furthermore, several empirical studies have reported that a dysfunctional ruminative process provokes distress and psychopathology. ${ }^{28-30}$ Therefore, higher levels of both dimensions of insecure attachment could be expected to correlate with excessive intrusive rumination, which might lead to complicated grief. Regarding deliberate rumination, one empirical study about romantic break-ups suggested that attachment anxiety correlates with deliberate rumination or reflection. ${ }^{23}$ Furthermore, other evidence has suggested that deliberate rumination plays an important role in post-traumatic growth. ${ }^{29,31}$ Therefore the hyper-activating strategies of attachment anxiety could lead to post-traumatic growth by promoting cognitive processing of traumatic loss-related thoughts such as deliberate rumination. $^{23,32}$

From that background, the present study tested a hypothesized model about an indirect pathway from attachment (X) through event-related rumination $(\mathrm{M})$ to a grief response (Y), including complicated grief and post-traumatic growth, in bereaved parents who lost children in the Sewol Ferry accident. In that accident, 339 of the passengers were high school students on a field trip, and 261 of them died. More than 500 parents lost their children in the accident, and they suffered serious psychological difficulties due to that traumatic loss. ${ }^{33}$ Specifically, the hypothesized model proposes that a higher level of both dimensions of insecure attachment would correlate positively with complicated grief via greater levels of intrusive rumination. Furthermore, it hypothesizes a significant indirect pathway from anxious attachment (X) (not avoidant attachment)through deliberate rumination $(\mathrm{M})$ to post-traumatic growth $(\mathrm{G})$.

\section{METHODS}

\section{Participants and procedures}

The present study was performed in the first year of a fouryear cohort study following the mental health of families bereaved in the Sewol Ferry accident. The detailed procedure for the study was described previously. ${ }^{33}$ A total of 81 bereaved 
parents who agreed to participate and completed all questionnaires were included in this study. The survey was performed an average of 18 months ( $\mathrm{SD}=1$ month) after the accident. Before the survey, interviewers obtained informed consent and told participants about the aim and importance of this study. The study procedure was approved by the Institutional Review Board of the ethical committee at Seoul St. Mary's Hospital at the Catholic University of Korea (KC15OIMI0261).

\section{Measurements}

Participants were evaluated for demographic variables: age, gender, years of education, marital status, and employment status. The different types of attachment, event-related rumination, complicated grief, and post-traumatic growth were evaluated using the instruments described below.

\section{Attachment}

Two dimensions of insecure attachment severity were assessed using the Experiences in Close Relationships Questionnaire-Short Form (ECR-S), ${ }^{34}$ a 12 -item measure that assesses adult romantic attachment using a seven-point Likert scale ranging from one (strongly disagree) to seven (strongly agree). Participants were instructed to respond based on how they generally experienced relationships with intimate partners. Items are grouped into two scales: attachment anxiety and attachment avoidance. In the present study, the Cronbach's alphas of the attachment anxiety and avoidance scales were 0.686 and 0.70 , respectively. The Korean version of the ECR-S was validated. ${ }^{35}$

\section{Event-related rumination}

Event-related intrusive and deliberate rumination were measured using the Event-related Rumination Inventory (ERRI), ${ }^{20}$ which assesses intrusive (10 items) and deliberate rumination (10 items) during the preceding two weeks. The items are rated on a six-point scale that ranges from zero (not at all) to five (always). Many of the participants in this study reported that they suffered from unwanted invasions of thoughts, memories, or images of their dead child, which could be categorized as intrusive rumination. Regarding deliberate rumination, some of them reported that they tried to think about the accident and understand what happened. The Cronbach's alphas of the subscales for intrusive rumination and deliberate rumination were 0.953 and 0.917 in the present population. The Korean version of the ERRI was validated. ${ }^{36}$

\section{Complicated grief}

The Inventory of Complicated Grief (ICG) was used to evaluate indicators of pathological grief. ${ }^{37}$ The instrument consists of 19 items that evaluate immediate bereavement-related thoughts and behaviors using five response options from "never" to "always." In the present sample, the Cronbach's alpha was 0.925 . The Korean version of the ICG was validated. ${ }^{38}$

\section{Post-traumatic growth}

Post-traumatic growth was measured 18 months after the accident using the short form of the Post-Traumatic Growth Inventory (PTGI-SF), ${ }^{39}$ which has 10 items. Each of the 10 items is scored on a six-point scale that ranges from one (no change) to six (very great degree of change). The Cronbach's alpha was 0.857 in the present study. The Korean version of the PTGI was validated. ${ }^{40}$

\section{Statistical analyses}

Descriptive statistics and Pearson's correlation coefficients were analyzed to investigate the associations among the different types of attachment, event-related rumination, complicated grief, and post-traumatic growth.

Item parceling was used to create the observed variables. Based on the recommended strategy, ${ }^{41}$ the factor loadings were used as a guide to assign items to parcels for each unidimensional latent construct (i.e., anxiety attachment, avoidance attachment, deliberate rumination, intrusive rumination, complicated grief, and post-traumatic growth). For example, after matching the highest loaded item with the lowest loaded item, their average was calculated. As a result, each latent variable contains three or more indicators. Because this study focuses on the overall structural model, not on investigating relationships among the items and measured variables, items that showed a factor loading below 0.5 were removed. The removed items are provided in Supplementary Table 1 (in the online-only Data Supplement).

Subsequently, the mediation model was tested using structural equation modeling (SEM). In the model, the independent variables (exogenous variables) were the sub-scores of anxious attachment and avoidant attachment. The dependent variables (endogenous variables) were the ICG and PTGI scores. The ERRI-intrusive and ERRI-deliberate sub-scores from the ERRI were mediating variables. Several goodnessof-fit measures were used to evaluate how well the hypothesized model fit the observed data: $\chi^{2}$, Tuker Lewis Index (TLI), comparative fit index (CFI), and root mean square error of approximation (RMSEA). Generally, a well-fitting model has a TLI or CFI of at least 0.90 and an RMSEA of 0.08 or lower. Finally, the significance of the indirect pathway was verified using bootstrapping. Descriptive statistics and measurement models fit to the observed variables were used to confirm whether the observed variables appropriately reflected the latent constructs. All analyses were performed in 
IBM SPSS Statistics software Version 22.0 (IBM Corp., Armonk, NY, USA) and IBM SPSS Amos 18.0 (SPSS Inc., Chicago, IL, USA).

\section{RESULTS}

\section{Participant demographics and psychosocial characteristics}

The demographics of participants are presented in Table 1. The mean age of the participants was $47.96( \pm 4.27)$ years, and $45.7 \%$ of the participants were men. A total of $19.5 \%$ of the participants were separated or divorced, and the mean for years of education was $14.05( \pm 2.77)$. A total of $23.5 \%$ of participants reported unemployment after the accident, and 19\% of participants reported a past psychiatric history. In addition, nine participants (11\%) reported that they were suffering from current psychiatric illness and getting treatment. Their diagnoses were depressive disorders (four), panic disorder (two), and insomnia (three). As described in a previous study, the majority of the bereaved parents still reported severe symp- toms of complicated grief, depression, and post-traumatic stress even though 18 months had passed since the accident. ${ }^{33}$ The mean ECR anxiety sub-score was $16.56( \pm 5.80)$, and the ECR avoidant sub-score was $22.65( \pm 4.72)$. The mean ERRIintrusive and ERRI-deliberatesub-scores were 19.77 ( \pm 7.10$)$ and $9.94( \pm 7.10)$, respectively. The mean ICG score was 52.55 $( \pm 14.38)$, and the mean PTGI score was $27.22( \pm 11.21)$.

\section{Correlations among different types of attachment, rumination, complicated grief, and post-traumatic growth}

The correlation matrix for all variables is provided in $\mathrm{Ta}$ ble 2. None of the variables were severely skewed or kurtotic. Attachment anxiety was positively correlated with deliberate rumination $(r=0.23, p<0.05)$. Attachment avoidance was negatively correlated with deliberate rumination $(r=-0.25$, $\mathrm{p}<0.05)$ and post-traumatic growth $(\mathrm{r}=-0.33, \mathrm{p}<0.01)$. The severity of complicated grief was positively correlated with attachment avoidance $(\mathrm{r}=0.26, \mathrm{p}<0.05)$ and intrusive rumination $(r=0.69, p<0.01)$. Post-traumatic growth was positively

Table 1. Characteristics of participants

\begin{tabular}{|c|c|c|c|c|}
\hline Characteristic & $\mathrm{M}(\%)$ & $\mathrm{SD}$ & Skewness & Kurtosis \\
\hline Age & 47.96 & 4.27 & & \\
\hline Gender (male) & 45.7 & & & \\
\hline Educational year & 14.05 & 2.77 & & \\
\hline Employment status (unemployment) & 23.5 & & & \\
\hline Marital status (married/cohabited) & 81.5 & & & \\
\hline Attachment anxiety (ECR-S_anxiety) & 16.56 & 5.80 & 0.31 & -0.13 \\
\hline Attachment avoidance (ECR-S_avoidance) & 22.65 & 4.72 & 0.07 & 1.57 \\
\hline Event related intrusive rumination (ERRI_intrusive) & 19.77 & 7.10 & -0.24 & -0.71 \\
\hline Event related deliberate rumination (ERRI_deliberate) & 9.94 & 7.10 & 0.50 & -0.16 \\
\hline Complicated grief (ICG) & 52.55 & 14.38 & -0.67 & -0.24 \\
\hline Posttraumatic growth (PTGI) & 27.22 & 11.21 & 0.91 & 0.15 \\
\hline
\end{tabular}

ECR-S_Anxiety: attachment anxiety subscales of the experience in close relationship questionnaire- short form, ECR-S_Avoidant: attachment avoidant subscales of the experience in close relationship questionnaire- short form, ERRI_Intrusive : intrusive rumination subscales of the event related rumination inventory, ERRI_Deliberate: deliberate rumination subscales of the event related rumination inventory, ICG: inventory of complicated grief, PTGI : posttraumatic growth inventory

Table 2. Correlations among attachment style, rumination, complicated grief and posttraumatic grief

\begin{tabular}{|c|c|c|c|c|c|c|}
\hline & $\begin{array}{l}\text { Attachment } \\
\text { anxiety }\end{array}$ & $\begin{array}{c}\text { Attachment } \\
\text { avoidance }\end{array}$ & $\begin{array}{c}\text { Intrusive } \\
\text { rumination }\end{array}$ & $\begin{array}{l}\text { Deliberate } \\
\text { rumination }\end{array}$ & $\begin{array}{c}\text { Complicated } \\
\text { grief }\end{array}$ & $\begin{array}{c}\text { Posttraumatic } \\
\text { growth }\end{array}$ \\
\hline Attachment anxiety & - & & & & & \\
\hline Attachment avoidance & 0.19 & - & & & & \\
\hline Intrusive rumination & 0.10 & 0.20 & - & & & \\
\hline Deliberate rumination & $0.23^{*}$ & $-0.25^{*}$ & 0.17 & - & & \\
\hline 5Complicated grief & 0.11 & $0.26^{*}$ & $0.69^{* *}$ & 0.06 & - & \\
\hline Posttraumatic growth & 0.13 & $-0.33^{* *}$ & -0.10 & $0.49^{* *}$ & -0.15 & - \\
\hline
\end{tabular}

${ }^{*} \mathrm{p}<0.05,{ }^{* *} \mathrm{p}<0.01$ 
correlated with deliberate rumination $(\mathrm{r}=0.49, \mathrm{p}<0.01)$.

\section{Indirect effect of insecure attachment on grief response via event-related rumination}

Figure 1 displays the model of the relationships between the two dimensions of attachment style and complicated grief/post-traumatic growth via rumination. The fit indices of the measurement model were acceptable $\left[\chi^{2}=301.44(\mathrm{df}=217\right.$, $\mathrm{p}<0.001), \mathrm{CFI}=0.93$, TLI $=0.91$, and $\mathrm{RMSEA}=0.07]$.

The test for direct effect in the model is presented in Table 3.
The path coefficients from attachment anxiety to deliberate rumination $(\beta=58, \mathrm{p}<0.05)$ and from deliberate rumination to post-traumatic growth $(\beta=0.45, \mathrm{p}<0.01)$ were significant. On the other hand, the paths from attachment anxiety to intrusive rumination and post-traumatic growth were not significant. The paths from attachment avoidance to intrusive rumination $(\beta=52, \mathrm{p}<0.05)$ and complicated grief $(\beta=0.55$, $\mathrm{p}<0.05)$ were significant. The path from intrusive rumination to complicated grief was also significant $(\beta=0.48, \mathrm{p}<0.01)$. However, the paths from attachment avoidance to deliberate

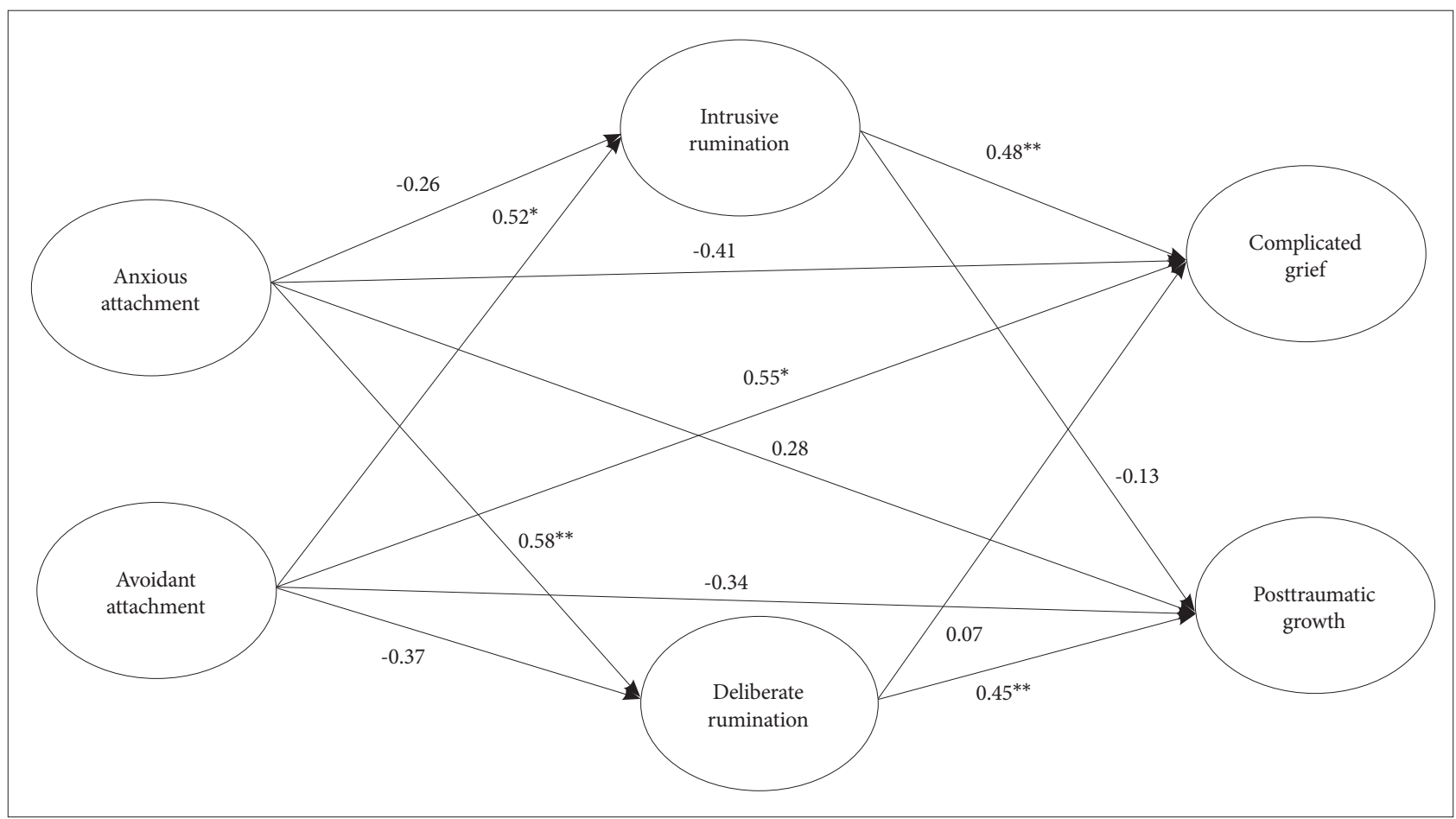

Figure 1. Mediation of relationship between attachment style, complicated grief/posttraumatic growth through rumination. Path coefficient was standardized. ${ }^{*} p<0.05,{ }^{* *} p<0.01$.

Table 3. The test of direct effect in the model of attachment style and complicated grief/posttraumatic growth, medicated by rumination

\begin{tabular}{|c|c|c|c|c|c|c|}
\hline Exogenous variable & & Endogenous variable & B & S.E. & $\beta$ & p-value \\
\hline \multirow[t]{4}{*}{ Attachment anxiety } & $\rightarrow$ & Intrusive rumination & -0.24 & 0.17 & -0.26 & 0.17 \\
\hline & $\rightarrow$ & Deliberate rumination & 0.46 & 0.17 & 0.58 & $<0.05$ \\
\hline & $\rightarrow$ & Complicated grief & -0.45 & 0.23 & -0.41 & 0.05 \\
\hline & $\rightarrow$ & Posttraumatic growth & 0.43 & 0.31 & 0.28 & 0.16 \\
\hline \multirow[t]{4}{*}{ Attachment avoidance } & $\rightarrow$ & Intrusive rumination & 0.37 & 0.15 & 0.52 & $<0.05$ \\
\hline & $\rightarrow$ & Deliberate rumination & -0.23 & 0.13 & -0.37 & 0.08 \\
\hline & $\rightarrow$ & Complicated grief & 0.60 & 0.15 & 0.55 & $<0.05$ \\
\hline & $\rightarrow$ & Posttraumatic growth & -0.41 & 0.25 & -0.34 & 0.11 \\
\hline \multirow[t]{2}{*}{ Intrusive rumination } & $\rightarrow$ & Complicated grief & 0.59 & 0.15 & 0.48 & $<0.01$ \\
\hline & $\rightarrow$ & Posttraumatic growth & -0.22 & 0.20 & -0.13 & 0.27 \\
\hline \multirow[t]{2}{*}{ Deliberate rumination } & $\rightarrow$ & Complicated grief & 0.10 & 0.17 & 0.07 & 0.56 \\
\hline & $\rightarrow$ & Posttraumatic growth & 0.57 & 0.26 & 0.45 & $<0.01$ \\
\hline
\end{tabular}


rumination and post-traumatic growth were not significant.

Table 4 provides the test for indirect effect in the model of attachment style and grief response mediated by rumination. Based on the bootstrapping test used to assess the significance of indirect effects, the indirect effect of attachment anxiety on post-traumatic growth via deliberate rumination was $\beta=0.16[p<0.05, C I=(0.01,0.32)]$. The indirect effect of attachment avoidance on complicated grief via intrusive rumination was $\beta=0.21[\mathrm{p}<0.05, \mathrm{CI}=(0.00,0.41)]$.

The proportion of indirect effect in the total effect is provided in Table 5. The proportion of the total effect that was explained by the indirect effect was 50\% in the path from attachment anxiety to post-traumatic growth. The proportion of indirect effect within the total effect was $29 \%$ in the path from attachment avoidance to complicated grief.

\section{DISCUSSION}

The present study investigated the possible mediating role of intrusive and deliberate rumination in the relationship between attachment anxiety and attachment avoidance and bereavement outcomes. A higher level of attachment avoidance was associated with more severe complicated grief via a greater level of intrusive rumination. Conversely, a higher level of attachment anxiety correlated with post-traumatic growth via a greater level of deliberate rumination. Although several previous studies suggested that the two different attachment styles might have distinctive influences on bereave- ment outcomes, few studies have considered possible cognitive mediating factors in the path from the different attachment styles to bereavement outcomes. ${ }^{23,42,43}$ Furthermore, most studies have investigated the grief response to natural deaths. The present study investigated a relatively homogenous group of participants that experienced traumatic loss in a single accident.

Consistent with the study hypothesis, a higher level of attachment anxiety correlated positively with post-traumatic growth via a greater level of deliberate rumination. This finding is consistent with several previous studies that found a positive association between attachment anxiety and posttraumatic growth after interpersonally stressful events. ${ }^{23,32}$ As explained above in the theoretical background, individuals with a high level of attachment anxiety tend to cope hyperactively with severely painful situations. ${ }^{44}$ Therefore, they may have more opportunity than others to deliberately ruminate about their loss as a way to overcome their painful experiences, which could lead to post-traumatic growth.

On the other hand, persons with attachment avoidance tend to lack trust in others and often suppress or avoid grief-related emotions. The avoidance of grief-related emotions can sometimes correlate with less-severe grief symptoms, as supported by many previous studies. ${ }^{45,46}$ However, considering that the participants in this study suffered from an extremely stressful situation, the loss of their children in a preventable accident, attempts to suppress or avoid painful emotion might not have been feasible, and intrusive rumination was likely to be prominent in a severe form. ${ }^{33}$ Such intrusive rumination could

Table 4. The test of indirect effect in the model of attachment style and complicated grief/posttraumatic growth, mediated by rumination

\begin{tabular}{lrrrr}
\hline \multicolumn{1}{c}{ Path } & \multirow{2}{*}{ Estimate } & p-value & \multicolumn{2}{c}{$95 \%$ bias-corrected CI } \\
\cline { 3 - 5 } & & & Lower & Upper \\
\hline Attachment avoidance $\rightarrow$ intrusive rumination $\rightarrow$ complicated grief & & 0.21 & 0.05 & 0.00 \\
Attachment avoidance $\rightarrow$ intrusive rumination $\rightarrow$ posttraumatic growth & -0.08 & 0.66 & -0.44 & 0.41 \\
Attachment avoidance $\rightarrow$ deliberate rumination $\rightarrow$ complicated grief & -0.02 & 0.94 & -0.47 & 0.28 \\
Attachment avoidance $\rightarrow$ deliberate rumination $\rightarrow$ posttraumatic growth & -0.17 & 0.23 & -0.45 & 0.43 \\
Attachment anxiety $\rightarrow$ intrusive rumination $\rightarrow$ complicated grief & -0.13 & 0.55 & -0.55 & 0.11 \\
Attachment anxiety $\rightarrow$ intrusive rumination $\rightarrow$ complicated grief & 0.04 & 0.81 & -0.29 & 0.37 \\
Attachment anxiety $\rightarrow$ deliberate rumination $\rightarrow$ posttraumatic growth & 0.03 & 0.91 & -0.48 & 0.53 \\
Attachment anxiety $\rightarrow$ deliberate rumination $\rightarrow$ posttraumatic growth & 0.16 & $<0.05$ & 0.01 & 0.32 \\
\hline
\end{tabular}

Table 5. The proportion of indirect effect to total effect

\begin{tabular}{lcccc}
\hline \multicolumn{1}{c}{ Path } & Total effect & Indirect effect & Direct effect & Indirect effect/total effect $(\%)$ \\
\hline Attachment anxiety $\rightarrow$ posttraumatic growth & $0.88(0.57)$ & $0.45(0.29)$ & $0.43(0.28)$ & 50 \\
Attachment anxiety $\rightarrow$ complicated grief & $-0.55(-0.49)$ & $-0.10(-0.09)$ & $-0.45(-0.41)$ & 17 \\
Attachment avoidance $\rightarrow$ posttraumatic growth & $-0.69(-0.57)$ & $-0.28(-0.23)$ & $-0.41(-0.34)$ & 40 \\
Attachment avoidance $\rightarrow$ complicated grief & $0.67(0.77)$ & $0.20(0.22)$ & $0.48(0.55)$ & 29 \\
\hline
\end{tabular}

The value in bracket is standardized coefficient 
make the grief process more complicated or prolonged in individuals with attachment avoidance.

However, inconsistent with the study hypothesis, the association between intrusive rumination and both dimensions of insecure attachment was not significant in the correlation analysis. In the overall mediation model, the path from attachment avoidance to intrusive rumination was significant, but the path from attachment anxiety to intrusive rumination was not. Although the degree of intrusive rumination is likely to be related to the post-traumatic distress level, intrusive thoughts are expected to occur as a normal byproduct of major stressful events. ${ }^{47}$ Because losing a child to a humancaused disaster is an extremely painful event, a substantial amount of intrusive rumination could be regarded as a normal process, rather than a pathological process. Therefore, it is possible that insecure attachment is not a significant contributing factor to the degree of intrusive rumination.

Regarding the indirect pathways tested here, the one from attachment avoidance through intrusive rumination to complicated grief was significant, but that path beginning from attachment anxiety was not. The different pathways from attachment anxiety and avoidance to bereavement outcomes might result from distinctive styles of cognitive processing about stressful events. A large body of literature suggests that individuals with different attachment styles cope differently with stressful experiences using distinctive cognitive processes. ${ }^{42,43,48,49}$ Several possible characteristics of the two attachment styles could have contributed to the present findings. First, with respect to attention bias level, individuals with attachment anxiety are more sensitive to both positive and negative interpersonal stimuli than securely attached persons. ${ }^{42}$ Such attention bias can contribute to a tendency to deliberately ruminate about both the positive and negative aspects of loss. ${ }^{42}$ Conversely, individuals with attachment avoidance tend to disengage from positive stimuli more efficiently and have difficulty disengaging from negative stimuli. ${ }^{43}$ Difficulty with eliminating negative stimuli could make them ruminate more intrusively about events, resulting in a negative reappraisal. Second, with respect to self-view, anxiously attached persons tend to view themselves negatively in terms of lovability and rejection. Such a negative self-view can be related to self-blaming but also self-reflection, ${ }^{50}$ which could motivate individuals to deliberately ruminate about loss, leading to post-traumatic growth.

Regarding the relative magnitude of the indirect effects within the total effects, the proportion of total effect explained by the indirect effect was $50 \%$ in the pathway from attachment anxiety to post-traumatic growth. In the pathway from attachment avoidance to complicated grief, a relatively smaller proportion of the total effect was explained by the indirect effect. These findings suggest that another mechanism, apart from ruminative style, could affect the severity of complicated grief in persons with attachment avoidance. On the other hand, deliberate rumination might be a key mechanism for post-traumatic growth in individuals with high levels of attachment anxiety. Multiple studies have investigated several other emotional regulation strategies related to the grief response. ${ }^{51-56}$ Based on those previous studies, the mediation effect of other cognitive or emotional regulation processes that might affect the paths between different types of attachment insecurity and the grief response should be investigated in the future, especially for attachment avoidance.

Overall, these findings indicate that grief interventions should be individualized by attachment style. For individuals with attachment anxiety, interventions that strengthen deliberate rumination might be valuable in promoting post-traumatic growth. Although undermining and managing intrusive rumination could be somewhat helpful for those with attachment avoidance, the effect might be small, and other clinical factors should also be considered to mitigate complicated grief.

In the current study, intrusive rumination did not correlate with deliberate rumination, which is inconsistent with the results of several previous studies. According to the theoretical model of post-traumatic growth, intrusive rumination provides cues to engage in the deliberate processing of traumatic events. ${ }^{57}$ Therefore, a positive association between the two types of rumination could be expected. Several empirical studies have supported that expectation, but others did not. ${ }^{29-31}$ It remains unclear whether the two types of rumination originate from similar or different cognitive mechanisms. Generally, intrusive rumination seems to occur soon after a traumatic event, affecting deliberate rumination later for most people. ${ }^{31,58}$ However, this study's cross-sectional design means that the present results cannot clarify the relationship between intrusive and deliberate rumination as a temporal sequence. Longitudinal studies are needed to investigate the temporal relationship between these two types of rumination.

The present study has several limitations. First, although there is no absolute rule for an adequate sample size in SEM, the sample size was relatively small compared with the previous literature. ${ }^{59}$ Therefore, we might have lacked adequate statistical power to detect an effect size of clinical importance. ${ }^{60}$ The possibility that some of the non-significance in the pathways was caused by the small sample size cannot be excluded. Furthermore, this study included only a small sample of all the bereaved Sewol parents; Informed consent was difficult to obtain for social and political reasons. Furthermore, the parents suffered from media attention and stigma. For these reasons, many bereaved parents declined to participate in 
any investigations for more than a year after the disaster, especially about their mental health. Selection bias must thus be considered because this study was limited to those who agreed to participate. In addition, several participants suffered from current major psychiatric illnesses that could have affected the outcome of this study. Although nine participants reported a current psychiatric illness, more participants might also have been suffering from clinically significant psychiatric illnesses, based on estimates from previous and present data. ${ }^{33}$ Therefore it is difficult to determine whether the existence of current psychiatric illnesses affected the present results. Second, many covariates, both demographic and clinical factors, that could have confounded the present results were not analyzed because the sample size was too small to consider them. Furthermore, as mentioned above, this study was cross-sectional, making it impossible to establish causal or temporal relationships among attachment, the two types of rumination, complicated grief, and post-traumatic growth. Establishing the temporal relationships between the two styles of rumination is theoretically important. Longitudinal studies are needed to follow up on changes in the two styles of rumination. Finally, all variables, including attachment, were assessed using self-report methods. It is possible that the parents distorted their mental representations of their relationships with their dead children. Furthermore, because no adult attachment interviews were performed, assessing and dividing the participants using all four types of attachment was impossible. For this reason, the secure and disorganized attachment types were not analyzed as variables in the present study. Therefore, interpretation of this result must be undertaken cautiously.

Despite its several limitations, the present study can provide insight into how attachment styles correlate with grief responses through two functionally different types of rumination, especially in response to severe types of traumatic loss. Attachment avoidance was associated with complicated grief via intrusive rumination. On the other hand, deliberate rumination had a significant indirect effect in the relationship between attachment anxiety and post-traumatic growth. These findings suggest that attachment style should be considered when helping individuals who have suffered from traumatic loss. In the future, longitudinal investigations about the influence of intrusive and deliberate rumination, which might have different effects according to attachment style, are needed.

\section{Supplementary Materials}

The online-only Data Supplement is available with this article at https://doi.org/10.30773/pi.2019.0291.

\section{Acknowledgments}

This study was supported by a grant of the Korea Health Technology
R\&D Project through the Korea Health Industry Development Institute (KHIDI), funded by the Ministry of Health \& Welfare, Republic of Korea (grant number: HL19C0007).

\section{Conflicts of Interest}

The authors have no potential conflicts of interest to disclose.

\section{Author Contributions}

Conceptualization: Hyu Jung Huh, Jeong-Ho Chae. Data curation: Jeong-Ho Chae. Formal analysis: Kyung Hee Kim, Hee-Kyung Lee. Funding acquisition: Jeong-Ho Chae. Investigation: all authors. Methodology: Hyu Jung Huh, Kyung Hee Kim, Hee-Kyung Lee. Project administration: JeongHo Chae. Resources: Jeong-Ho Chae. Software: Jeong-Ho Chae. Supervision: Jeong-Ho Chae. Validation: Jeong-Ho Chae. Visualization: Hyu Jung Huh. Writing_original draft: Hyu Jung Huh. Writing—review \& editing: all authors.

\section{ORCID iDs}

Hyu Jung Huh Kyung Hee Kim Hee-Kyung Lee Jeong-Ho Chae https://orcid.org/0000-0001-8050-9189

https://orcid.org/0000-0003-1009-9203

https://orcid.org/0000-0002-6854-8772 https://orcid.org/0000-0002-6070-9324

\section{REFERENCES}

1. Stroebe M, Schut H, Stroebe W. Health outcomes of bereavement. Lancet 2007;370:1960-1973.

2. Gerrish N, Dyck MJ, Marsh A. Post-traumatic growth and bereavement. Mortality 2009;14:226-244.

3. Shear K. Adapting Imaginal Exposure to the Treatment of Complicated Grief. In: Rothbaum BO, Editor. Pathological Anxiety: Emotional Processing in Etiology and Treatment. New York, NY; Guilford Press, 2006, p.215-226.

4. Shear K, Shair H. Attachment, loss, and complicated grief. Dev Psychobiol 2005;47:253-267.

5. Stroebe M, Schut H, Stroebe W. Attachment in coping with bereavement: a theoretical integration. Rev Gen Psychol 2005;9:48-66.

6. Mikulincer M, Gillath O, Shaver PR. Activation of the attachment system in adulthood: threat-related primes increase the accessibility of mental representations of attachment figures. J Pers Soc Psychol 2002; 83:881-895.

7. Meredith P, Strong J, Feeney JA. Adult attachment, anxiety, and pain self-efficacy as predictors of pain intensity and disability. Pain 2006;123: 146-154.

8. Wei M, Russell DW, Mallinckrodt B, Vogel DL. The Experiences in Close Relationship Scale (ECR)-short form: reliability, validity, and factor structure. J Pers Assess 2007;88:187-204.

9. Mikulincer M, Shaver PR. Attachment in Adulthood: Structure, Dynamics, and Change. New York, NY: Guilford Press; 2007.

10. Vrticka P, Vuilleumier P. Neuroscience of human social interactions and adult attachment style. Front Hum Neurosci 2012;6:212.

11. Mikulincer M, Florian V. Appraisal of and coping with a real-life stressful situation: The contribution of attachment styles. Pers Soc Psychol Bull 1995;21:406-414.

12. Fraley RC, Bonanno GA. Attachment and loss: a test of three competing models on the association between attachment-related avoidance and adaptation to bereavement. Pers Soc Psychol Bull 2004;30:878-890.

13. Turunen T, Haravuori H, Punamaki RL, Suomalainen L, Marttunen $\mathrm{M}$. The role of attachment in recovery after a school-shooting trauma. Eur J Psychotraumatol 2014;5.

14. Salo JA, Qouta S, Punamäki RL. Adult attachment, posttraumatic growth and negative emotions among former political prisoners. Anxiety Stress Coping 2005;18:361-378.

15. Dekel R. Posttraumatic distress and growth among wives of prisoners of war: the contribution of husbands' posttraumatic stress disorder and wives' own attachments. Am J Orthopsychiatry 2007;77:419-426. 
16. Spielman V, Taubman-Ben-Ari O. Parental self-efficacy and stress-related growth in the transition to parenthood: A comparison between parents of pre- and full-term babies. Health Soc Work 2009;34:201-212.

17. Nolen-Hoeksema S, Wisco BE, Lyubomirsky S. Rethinking Rumination. Perspect Psychol Sci 2008;3:400-424.

18. García FE, Duque A, Cova F. The four faces of rumination to stressful events: a psychometric analysis. Psychol Trauma 2017;9:758-765.

19. Janoff-Bulman R. Shattered Assumptions: Towards a New Psychology of Trauma. New York, NY; Free Press; 1992.

20. Cann A, Calhoun LG, Tedeschi RG, Triplett KN, Vishnevsky T, Lindstrom CM. Assessing posttraumatic cognitive processes: the Event Related Rumination Inventory. Anxiety Stress Coping 2011;24:137-156.

21. Calhoun LG, Cann A, Tedeschi RG, McMillan J. A correlational test of the relationship between posttraumatic growth, religion, and cognitive processing. J Trauma Stress 2000;13:521-527.

22. Van Durme K, Goossens L, Bosmans G, Braet C. The role of attachment and maladaptive emotion regulation strategies in the development of bulimic symptoms in adolescents. J Abnorm Child Psychol 2018; 46:881-893.

23. Marshall TC, Bejanyan K, Ferenczi N. Attachment styles and personal growth following romantic breakups: the mediating roles of distress, rumination, and tendency to rebound. PLoS One 2013;8:e75161.

24. Tremblay I, Sullivan MJ. Attachment and pain outcomes in adolescents: the mediating role of pain catastrophizing and anxiety. J Pain 2010;11: 160-171.

25. Pearson KA, Watkins ER, Mullan EG, Moberly NJ. Psychosocial correlates of depressive rumination. Behav Res Ther 2010;48:784-791.

26. Burnette JL, Taylor KW, Worthington EL, Forsyth DR. Attachment and trait forgivingness: the mediating role of angry rumination. Pers Individ Diff 2007;42:1585-1596.

27. Lanciano T, Curci A, Kafetsios K, Elia L, Zammuner VL. Attachment and dysfunctional rumination: the mediating role of Emotional Intelligence abilities. Pers Individ Diff 2012;53:753-758.

28. Morina N. Rumination and avoidance as predictors of prolonged grief, depression, and posttraumatic stress in female widowed survivors of war. J Nerv Ment Dis 2011;199:921-927.

29. Taku K, Calhoun LG, Cann A, Tedeschi RG. The role of rumination in the coexistence of distress and posttraumatic growth among bereaved Japanese university students. Death Stud 2008;32:428-444.

30. Zhou $\mathrm{X}, \mathrm{Wu} \mathrm{X}$. The relationship between rumination, posttraumatic stress disorder, and posttraumatic growth among Chinese adolescents after earthquake: a longitudinal study. J Affect Disord 2016;193:242-248.

31. Zhou X, Wu X, Fu F, An Y. Core belief challenge and rumination as predictors of PTSD and PTG among adolescent survivors of the Wenchuan earthquake. Psychol Trauma 2015;7:391-397.

32. Xu W, Fu Z, He L, Schoebi D, Wang J. Growing in times of grief: Attachment modulates bereaved adults' posttraumatic growth after losing a family member to cancer. Psychiatry Res 2015;230:108-115.

33. Huh HJ, Huh S, Lee SH, Chae JH. Unresolved bereavement and other mental health problems in parents of the Sewol ferry accident after 18 Months. Psychiatry Investig 2017;14:231-239.

34. Wei M, Russell DW, Mallinckrodt B, Vogel DL. The Experiences in Close Relationship Scale (ECR)-short form: reliability, validity, and factor structure. J Pers Assess 2007;88:187-204.

35. Lee JY, Shin YJ. Experience in close relationships scale-short version (ECR-S) validation with korean college students. Meas Eval Couns Dev 2019;52:119-127

36. Ahn HN, Joo HS, Sim KS, Min JW. Validation of the event related rumination inventory in a Korean population. Cogn Behav Ther 2013;13: 149-172.

37. Prigerson HG, Maciejewski PK, Reynolds CF 3rd, Bierhals AJ, Newsom JT, Fasiczka A, et al. Inventory of complicated grief: a scale to measure maladaptive symptoms of loss. Psychiatry Res 1995;59:65-79.

38. Hahn DH, Lee JJ, Moon DS, Cha MJ, Kim MA, Min SY, et al. Korean version of inventory of complicated grief scale: psychometric properties in Korean adolescents. J Korean Med Sci 2016;31:114-119.

39. Cann A, Calhoun LG, Tedeschi RG, Taku K, Vishnevsky T, Triplett
$\mathrm{KN}$, et al. A short form of the Posttraumatic Growth Inventory. Anxiety Stress Coping 2010;23:127-137.

40. Song SH. Reliability and Validity of the Korean Version of the Posttraumatic Growth Inventory. Psychology. Dea Jeon: Chung Nam University; 2007.

41. Little TD, Cunningham WA, Shahar G, Widaman KF. To parcel or not to parcel: Exploring the question, weighing the merits. Struct Equ Modeling 2002;9:151-173.

42. Donges US, Kugel H, Stuhrmann A, Grotegerd D, Redlich R, Lichev V, et al. Adult attachment anxiety is associated with enhanced automatic neural response to positive facial expression. Neuroscience 2012;220: 149-157.

43. Liu Y, Ding Y, Lu L, Chen X. Attention bias of avoidant individuals to attachment emotion pictures. Sci Rep 2017;7:41631.

44. Bartholomew K. Avoidance of intimacy: an attachment perspective. J Soc Pers Relat 1990;7:147-178.

45. Boelen PA, Klugkist I. Cognitive behavioral variables mediate the associations of neuroticism and attachment insecurity with prolonged grief disorder severity. Anxiety Stress Coping 2011;24:291-307.

46. Kho Y, Kane RT, Priddis L, Hudson J. The nature of attachment relationships and grief responses in older adults: An attachment path model of grief. PLoS One 2015;10:e0133703.

47. Cann A, Calhoun LG, Tedeschi RG, Triplett KN, Vishnevsky T, Lindstrom CM. Assessing posttraumatic cognitive processes: the Event Related Rumination Inventory. Anxiety Stress Coping 2011;24:137-156.

48. McWilliams LA, Asmundson GJ. The relationship of adult attachment dimensions to pain-related fear, hypervigilance, and catastrophizing. Pain 2007;127:27-34.

49. Sambo CF, Howard M, Kopelman M, Williams S, Fotopoulou A. Knowing you care: effects of perceived empathy and attachment style on pain perception. Pain 2010;151:687-693.

50. Bartholomew K, Horowitz LM. Attachment styles among young adults: a test of a four-category model. J Pers Soc Psychol 1991;61:226-244.

51. Gupta S, Bonanno GA. Complicated grief and deficits in emotional expressive flexibility. J Abnorm Psychol 2011;120:635-643.

52. Eisma MC, Stroebe MS, Schut HA, Stroebe W, Boelen PA, van den Bout J. Avoidance processes mediate the relationship between rumination and symptoms of complicated grief and depression following loss. J Abnorm Psychol 2013;122:961-970.

53. Tay AK, Mohsin M, Rees S, Tam N, Kareth M, Silove D. The structure and psychosocial correlates of complicated bereavement amongst refugees from West Papua. Soc Psychiatry Psychiatr Epidemiol 2019;54: 771-780.

54. Skritskaya NA, Mauro C, Olonoff M, Qiu X, Duncan S, Wang Y, et al. Measuring maladaptive cognitions in complicated grief: introducing the typical beliefs questionnaire. Am J Geriatr Psychiatry 2017;25:541-550.

55. Baker AW, Keshaviah A, Horenstein A, Goetter EM, Mauro C, Reynolds $\mathrm{C}$ 3rd, et al. The role of avoidance in complicated grief: a detailed examination of the Grief-Related Avoidance Questionnaire (GRAQ) in a large sample of individuals with complicated grief. J Loss Trauma 2016;21:533-547.

56. Currier JM, Irish JE, Neimeyer RA, Foster JD. Attachment, continuing bonds, and complicated grief following violent loss: testing a moderated model. Death Stud 2015;39:201-210.

57. Calhoun LG, Tedeschi RG. The Foundations of Posttraumatic Growth: An Expanded Framework. In: Calhoun LG, Tedeschi RG, Editors. Handbook of Posttraumatic Growth: Research \& Practice. Mahwah, NJ; Lawrence Erlbaum Associates Publishers, 2006, p.3-23.

58. Lindstrom CM, Cann A, Calhoun LG, Tedeschi RG. The relationship of core belief challenge, rumination, disclosure, and sociocultural elements to posttraumatic growth. Psychol Trauma 2013;5:50-55.

59. Wolf EJ, Harrington KM, Clark SL, Miller MW. Sample size requirements for structural equation models: an evaluation of power, bias, and solution propriety. Educ Psychol Meas 2013;76:913-934.

60. Pan H, Liu S, Miao D, Yuan Y. Sample size determination for mediation analysis of longitudinal data. BMC Med Res Methodol 2018;18:32. 
Supplementary Table 1. The used/removed items in item parceling of the model of attachment type and complicated grief/posttraumatic growth, medicated by rumination

\begin{tabular}{lll}
\hline \multicolumn{1}{c}{ Variables } & \multicolumn{1}{c}{ Used items } & Removed items \\
\hline Attachment (ECR-S) & ECR-S 2, 3, 6, 7, 10, 11, 12 & ECR-S 1, 4, 5, 8, 9 \\
Rumination (K-ERRI) & K-ERRI 1-20 & None \\
Complicated grief (ICG) & ICG 1, 2, 4, 5, 6, 7, 9, 10, 1, 12, 13, 14, 15, 16, 17 & ICG 3, 8, 18, 19 \\
Posttraumatic growth (PTGI) & PTGI 2, 3, 6, 7, 9 & PTGI 1, 4, 8, 10 \\
\hline
\end{tabular}

